\title{
Profiles of messenger RNAs and MicroRNAs in hypoxia-induced hepatic stellate cells
}

\author{
Liting Zhang ${ }^{1,2,3 \#}$, Jing Gao ${ }^{4 \#}$, Dan Zhou ${ }^{5 \#}$, Xiaojun Wang ${ }^{6,7}$, Junfeng Li $^{3}$, Juan Wang ${ }^{8}$, Hong Chen ${ }^{3,8}$, \\ Xiaodong Xie ${ }^{9}$, Tuo Chen ${ }^{1,2}$
}

${ }^{1}$ State Key Laboratory of Cryospheric Science, Northwest Institute of Eco-Environment and Resources, Chinese Academy of Sciences, Lanzhou, China; ${ }^{2}$ University of Chinese Academy of Sciences, Beijing, China; ${ }^{3}$ Department of Infectious Diseases, The First Hospital of Lanzhou University, Lanzhou, China; ${ }^{4}$ Respiratory Medicine Unit, Department of Medicine, Karolinska Institute, Stockholm, Sweden; ${ }^{5}$ Department of Liver Diseases, The First Hospital of Lanzhou University, Lanzhou, China; ${ }^{6}$ Department of Respiratory Medicine, Gansu Provincial Hospital, Lanzhou, China; ${ }^{7}$ The First School of Clinical Medicine, Lanzhou University, Lanzhou, China; ${ }^{8}$ Department of Gastroenterology, Xi'an International Medical Center, Xi'an, China; 'Institute of Medical Genetics, School of Basic Medical Sciences, Lanzhou University, Lanzhou, China

Contributions: (I) Conception and design: L Zhang, X Xie, T Chen; (II) Administrative support: None; (III) Provision of study materials or patients: L Zhang, H Chen; (IV) Collection and assembly of data: L Zhang, D Zhou; (V) Data analysis and interpretation: L Zhang, D Zhou, J Gao, X Wang, J Li, J Wang; (VI) Manuscript writing: All authors; (VII) Final approval of manuscript: All authors.

"These authors contributed equally to this work.

Correspondence to: Tuo Chen. State Key Laboratory of Cryospheric Science, Northwest Institute of Eco-Environment and Resources, Chinese Academy of Sciences, Lanzhou 730000, China; University of Chinese Academy of Sciences, Beijing 100049, China. Email: chentuo@lzb.ac.cn; Xiaodong Xie. Key Laboratory of Preclinical Study for New Drug of Gansu Province, School of Basic Medical Sciences, Lanzhou University, Lanzhou 730000, China. Email: xdxie@lzu.edu.cn.

Background: MicroRNA (miRNA) plays an important role in hepatic stellate cell (HSCs) activation and liver fibrosis. The purpose of this study is to explore the effect of hypoxia on the differential expression of mRNAs and miRNAs in rat HSCs.

Methods: HSC-T6 cells were treated with cobalt chloride $\left(\mathrm{CoCl}_{2}\right)$, and the activity of HSC-T6 cells was measured by the CCK- 8 assay. The mRNA expression levels of hypoxia inducible factor- $1 \alpha(\mathrm{HIF}-1 \alpha)$, collagen type I, transforming growth factor- $\beta 1$ (TGF- $\beta 1$ ), and Smad7 were measured by RT-qPCR. The protein expression levels of HIF-1 $\alpha$, Bax, Bcl-2, and caspase- 3 were assayed by western blot. We used basal medium and $400 \mu \mathrm{mol} / \mathrm{L} \mathrm{CoCl}{ }_{2}$ medium to treat HSC-T6 cells for $48 \mathrm{~h}$. Cells were harvested after $48 \mathrm{~h}$ to extract RNA. Transcriptome sequencing was performed to investigate differentially expressed miRNAs and mRNAs (fold change $>2 ; \mathrm{P}<0.05$ ). Bioinformatics analysis was performed to predict the functions of differentially expressed miRNAs and mRNAs. Further, we used RT-qPCR to detect the expression of mRNAs and miRNAs to confirm the accuracy of sequencing.

Results: With the increase of $\mathrm{CoCl}_{2}$ concentration, the activity of HSC-T6 cells decreased $(\mathrm{P}<0.05)$. The mRNA expression levels of HIF- $1 \alpha$, collagen I, TGF- $\beta 1$, and Smad7, and the protein expressions levels of HIF-1 $\alpha$, Bax, caspase-3, and the Bcl-2/Bax ratio were increased compared with the control group $(\mathrm{P}<0.05)$, while the expression of Bcl-2 decreased. A total of 54 miRNAs (20 upregulated and 34 downregulated) and 1,423 mRNAs (685 upregulated and 738 downregulated) were differentially expressed in the $400 \mu \mathrm{mol} / \mathrm{L}$ $\mathrm{CoCl}_{2}$ medium group compared to the control basal medium group. Further bioinformatics analysis demonstrated that the differentially expressed mRNAs and miRNAs were mainly enriched in the synthesis of extracellular matrix. In addition, we used RT-qPCR to detect the expression of mRNAs and miRNAs to confirm the accuracy of sequencing.

^ ORCID: 0000-0003-1337-5461. 


\begin{abstract}
Conclusions: Our results presented the profiles of mRNAs and miRNAs in hypoxia-induced HSC-T6 cells in rats, the signaling pathways, and co-expression networks. These findings may suggest novel insights for the early diagnosis and treatment of HSC activation and liver fibrosis.
\end{abstract}

Keywords: Hypoxia; rat hepatic stellate cells (HSCs); genome sequencing; hypoxia inducible factor-1 alpha (HIF-1 $\alpha)$; miRNA

Submitted Jul 22, 2021. Accepted for publication Sep 18, 2021.

doi: $10.21037 / \mathrm{atm}-21-4215$

View this article at: https://dx.doi.org/10.21037/atm-21-4215

\section{Introduction}

Liver fibrosis is the common outcome of several chronic liver diseases, eventually leading to cirrhosis and liver cancer. The activation of hepatic stellate cells (HSCs) is the core process in the development of liver fibrosis $(1,2)$. Although some progress has been made in antiliver fibrosis treatment in recent years, there are still many patients with advanced liver disease. Therefore, clarifying the detailed mechanism of HSCs activation will provide an effective therapeutic approach for the treatment of liver fibrosis. Hypoxia is a common pathophysiological process. Increasing evidence has indicated that hypoxia can promote the activation of HSCs and accelerate the progression of liver fibrosis (3-5). In addition, hypoxia could promote the secretion of liver fibrosis factors such as collagen I and Alpha-smooth muscle actin ( $\alpha$-SMA) (6). However, the underlying mechanism of HSC activation caused by hypoxia is still unclear.

MicroRNAs (miRNA) are defined as small non-coding RNA molecules with a length of about 18-24 nucleotides, regulating embryonic development, cell proliferation, differentiation, signal transduction complex biological processes $(7,8)$. They participate in the regulation of target gene expression mainly through incomplete pairing and binding with the $3^{\prime}$ or $5^{\prime}$ untranslated regions (UTRs) of their target mRNAs to inhibit target gene mRNA transcription, translation $(9,10)$. Numerous studies have indicated that several miRNAs play important roles in the activation of HSCs and the development of liver fibrosis. For example, miR-145, miR-146b, miR-214, and miR942 can promote the activation of HSCs (11-14). MiR-122 regulates collagen production by targeting HSCs $(8,15)$. In addition, several miRNAs have been found to be consistently modulated during liver fibrosis, such as miR-15b, miR-16, miR-19a, miR-19b, miR-21 and so on (16). Although these studies have shown the importance of miRNAs in HSC activation, the changes of miRNAs in HSCs under hypoxic conditions still need to be clarified. RNA-sequencing analyzes the expression of various genes under pathological conditions, and may contribute novel insights into understanding the mechanisms of diseases. Furthermore, the development of bioinformatics can better clarify the complexity of biological processes and diseases (17).

Hence, determining the expression of miRNAs and mRNAs under hypoxic conditions may provide new targets for the treatment of liver fibrosis. The present study aimed to analyze the differentially expressed miRNAs and mRNAs in the HSC-T6 cell line induced by cobalt chloride $\left(\mathrm{CoCl}_{2}\right)$ via transcriptome sequencing. Bioinformatics analyses, including Gene Ontology (GO) and Kyoto Encyclopedia of Genes and Genomes (KEGG) pathway analysis, were used to clarify the biological functions of differentially expressed miRNAs and mRNAs. In order to verify the RNA sequencing data, reverse transcription quantitative polymerase chain reaction (RT-qPCR) was performed, and miRNAs with significantly different expression were identified. This can further screen diagnostic biomarkers and therapeutic targets for liver fibrosis. We present the following article in accordance with the MDAR reporting checklist (available at https://dx.doi. org/10.21037/atm-21-4215).

\section{Methods}

\section{Materials}

The rat HSC cell line HSC-T6 was donated by Professor Dr. Hong Chen, Xi'an International Medical Center, Xi'an, China. Dulbecco's modified Eagle's medium (DMEM, Hyclone, USA), penicillin/streptomycin (Sigma, USA), fetal bovine serum (FBS, Hyclone, USA), trypsin (Sigma, USA), $\mathrm{CoCl}_{2}$ (Sigma, USA), CCK-8 kit (Nanjing, China), TRIzol reagent (Invitrogen, USA), reverse transcription kit (Roche, Transcriptor First Strand cDNA Synthesis Kit, 
Table 1 Primer sequences

\begin{tabular}{ll}
\hline Primer name & Primer sequence \\
\hline HIF-1 $\alpha$ & Forward: CGGGATCCTCTCTAGTCTCACGAGG \\
& GGTTTC \\
& $\begin{array}{l}\text { Reverse: GCTCTAGAGATGCTACTGCAATGCAAT } \\
\text { GGTT }\end{array}$ \\
Collagen I & Forward: GTGCTAAAGGTGCCAATGGT \\
& Reverse: ACCAGGTTCACCGCTGTTAC \\
TGF- $\beta 1$ & Forward: CGCGTGCTAATGGTGGAAA \\
& Reverse: CGCTTCTCGGAGCTCTGATG \\
Smad7 & Forward: TCCTGCTGTGCAAAGTGTTC \\
& Reverse: AGTAAGGAGGAGGGGGAGAC \\
& Forward: GAAACTACCTTCAACTCCATC \\
& Reverse: CTAGAAGCATTGGGGTGAC \\
\hline
\end{tabular}

Switzerland), fluorescence quantitative PCR kit (Roche, FastStart SYBR ${ }^{\circledR}$ Green Master, Switzerland), BCA kit (Beyotime, China), SDS-PAGE (Beyotime, China), polyvinylidene fluoride (PVDF ) membranes (Millipore, USA), and hypoxia inducible factor-1 $\alpha$ (HIF-1 $\alpha)$, caspase-3, $\beta$-actin (Santa Cruz Biotechnology Inc., USA), Bax, and Bcl-2 (Bioworld Technology Inc., USA) antibodies were used in our experiments.

\section{Cell culture}

HSC-T6 cells were cultured in DMEM medium (Hyclone, USA) containing $10 \%$ FBS (Hyclone, USA) and $1 \mathrm{mg} / \mathrm{mL}$ penicillin and streptomycin (Sigma, USA) and incubated at $37{ }^{\circ} \mathrm{C}$ with $5 \% \mathrm{CO}_{2}$. In the later stage, the medium was changed and passaged according to the growth of the cells, and 3-5 generations of cells were used in the follow-up experiments.

\section{Establishment of the bypoxic microenvironment}

$\mathrm{CoCl}_{2}$ (Sigma, USA) was used to establish a hypoxic microenvironment for cells. In the experiment, $0.238 \mathrm{~g}$ of $\mathrm{CoCl}_{2}$ hexahydrate powder was weighed in $10 \mathrm{~mL}$ of sterilized triple-distilled water to prepare a storage solution with a final concentration of $100 \mathrm{mM}$. According to the concentration gradient of $\mathrm{CoCl}_{2}$ required in the experiment, we diluted the $100 \mathrm{mM} \mathrm{CoCl} 2$ mother liquor into culture solutions with final concentrations of 0,100 ,
200, 400, and $800 \mu \mathrm{mol} / \mathrm{L}$. HSC-T6 cells were treated with $\mathrm{CoCl}_{2}$ at different concentrations $(0,100,200,400$, $800 \mu \mathrm{mol} / \mathrm{L}$ ) for 24 and $48 \mathrm{~h}$ to establish a cellular hypoxic microenvironment.

\section{Cell viability assay}

The CCK-8 assay (Nanjing, China) was used to assess cell viability. The HSC-T6 cells were plated in 96-well plates at a density of 3,000 cells/well. Following incubation at $37^{\circ} \mathrm{C}$ for 24 and $48 \mathrm{~h}$ time intervals, the optical density (OD ) values of absorbance were determined using a microplate reader (Bio-Rad, USA) at a wavelength of $450 \mathrm{~nm}$, in accordance with the manufacturer's protocol. All experiments were performed in triplicate. The cell survival rate of each group was calculated according to the OD value. Cell survival rate $=($ experimental group OD value-blank well OD value $) /(\mathrm{OD}$ value of control group-blank well).

\section{Cell pre-treatment}

HSC-T6 cells were cultured in conventional medium (3 groups) and medium containing $400 \mu \mathrm{mol} / \mathrm{L} \mathrm{CoCl}_{2}$ ( 3 groups) for $48 \mathrm{~h}$. After $48 \mathrm{~h}$, the total RNA in the cells of each group was extracted for follow-up experiments.

\section{RT-qPCR analysis}

RT-qPCR was performed to detect HIF- $1 \alpha$, collagen I, TGF- $\beta 1$, and Smad7 mRNA expression. The total RNA of each group was extracted using the TRIzol reagent (Invitrogen, USA) after HSC-T6 cells were treated with $\mathrm{CoCl}_{2}$ at different concentrations $(0,50,100,200$, $400 \mu \mathrm{mol} / \mathrm{L})$ for $48 \mathrm{~h}$. The corresponding cDNA was obtained using the reverse transcription kit (Roche, Transcriptor First Strand cDNA Synthesis Kit, Switzerland). The mRNA levels of the above-mentioned factors were detected by the fluorescence quantitative PCR kit (Roche, FastStart SYBR ${ }^{\circledR}$ Green Master, Switzerland) with cDNA as the template and $\beta$-actin as the internal reference. The primer sequences are shown in Table 1, synthesized by Jiang Lai company. The expressions levels of the target genes were determined by the $2^{-\Delta \Delta \mathrm{Ct}}$ method.

To confirm the accuracy of gene sequencing analysis, the expression of 3 miRNAs and 3 mRNAs was measured by RT-qPCR using the SYBR-Green method (PerfectStart ${ }^{\text {TM }}$ Green qPCR SuperMix) and a LightCycler ${ }^{\circledR} 480$ Type II fluorescence quantitative PCR instrument (Roche, 
Table 2 miRNA primer sequences

\begin{tabular}{llc}
\hline miRNA & Forward primer $\left(5^{\prime}\right.$-3') & $\mathrm{Tm}\left({ }^{\circ} \mathrm{C}\right)$ \\
\hline rno-miR-23a-5p & TTCCTGGGGATGGGATTAAA & 60 \\
novel11_star & GGTTGGGGATTTCGCTCAGT & 60 \\
novel32_mature & CCTGGTGGGCCCTGCAAA & 60 \\
novel500_mature & CGGAGGCTGTAGGTCCAAA & 60 \\
novel591_mature & ACAGATGGCTGGCTGAGAAA & 60 \\
novel783_mature & ACAGCAGGCACAGACAGAAA & 60 \\
rno-miR-145-3p & GGATTCCTGGAAATACTGTTC & 60 \\
rno-miR-351-5p & AGGAGCCCTTTGAGCCTGA & 60 \\
rno-miR-702-3p & CCCTTTACCCCACTCCAAAA & 60 \\
5S & GGAGACCGCCTGGGAATA & 60 \\
\hline
\end{tabular}

Switzerland). Total RNA was extracted from HSC-T6 cells using lysis/binding buffer, and cDNA was synthesized (TransScript miRNA First-Strand cDNA Synthesis SuperMIX) with the following reaction conditions: $37^{\circ} \mathrm{C}$ $60 \mathrm{~min}, 85^{\circ} \mathrm{C} 5 \mathrm{~s}$, and $-20^{\circ} \mathrm{C}$ save. All of the primers (Table 2) used for RT-qPCR were designed by Shanghai Ouyi Biomedical Technology Co., Ltd and synthesized by Beijing Jingke Xinye Biotechnology Co., Ltd. PCR was performed under the following conditions: pre-denaturation for $30 \mathrm{~s}$ at $94{ }^{\circ} \mathrm{C}$ with cycling, denaturation for $5 \mathrm{~s}$ at $94{ }^{\circ} \mathrm{C}$, annealing for $30 \mathrm{~s}$ at $60{ }^{\circ} \mathrm{C}$ with 45 cycles from denaturation to extension. The expression of each gene was calculated using the $2^{-\Delta \Delta \mathrm{Ct}}$ method and normalized to that of $\mathrm{ACTB} / 5 \mathrm{~S}$.

\section{Western blot}

HSC-T6 cells treated with different concentrations of $\mathrm{CoCl}_{2}(0,50,100,200,400 \mu \mathrm{mol} / \mathrm{L})$ were added to RIPA protein lysate to extract the total proteins. The protein concentration of each group was determined by the BCA method (Beyotime, China), and SDS-PAGE (Beyotime, China) was performed. After electrophoresis, proteins were transferred to a PVDF membrane (Millipore, USA). After blocking with $5 \%$ skimmed milk powder for $1 \mathrm{~h}$, the membrane was incubated with primary antibodies against HIF-1 $\alpha$, caspase-3 (Santa Cruz Biotechnology Inc., USA), Bax, and Bcl-2 (Bioworld Technology Inc., USA) at $4{ }^{\circ} \mathrm{C}$ overnight. After washing, the membrane was incubated with horseradish peroxidase-conjugated secondary antibody at room temperature for $1 \mathrm{~h}$. Finally, the ECL kit was used to develop color. $\beta$-actin (Santa Cruz Biotechnology Inc, USA) was used as an internal reference.

\section{Transcriptome sequencing analysis}

The total RNA of each group was extracted from HSC-T6 cells with the TRIzol reagent (Invitrogen, USA), according to the manufacturer's protocol. RNA concentration was determined by NanoDrop 2000 (Thermo Fisher Scientific, USA), and the quality of RNA was evaluated using Agilent 2100 (Agilent Technologies, USA) and 1\% agarose gel electrophoresis. The total RNA sample quality had to meet the experimental requirements RNA integrity number (RIN) $\geq 7$ and $28 \mathrm{~S} / 18 \mathrm{~S} \geq 0.7$ for the construction of the cDNA library and subsequent genome sequencing.

According to the TruSeq Stranded Total RNA with Ribo-Zero Gold kit (Illumina, RS-122-2301, USA) reagent manufacturer's instructions, the ribosomal RNA was removed, and the interrupting reagent was added to cleave the RNA into short fragments. Using the interrupted RNA as a template, a strand of cDNA was synthesized with reverse transcriptase and six-base random primers. Then, a two-strand synthesis reaction system was prepared to synthesize two-strand cDNA. After connecting the twostrand cDNA to different linkers, the one strand containing dUTP was digested by the UNG enzymatic method, and only the first strand of cDNA with different linkers in the connecting strand was retained. The cDNA strand was purified, the end of the purified cDNA strand was repaired, poly A tail was added and the sequencing connector was connected, then the fragments of suitable size were amplified by PCR. The length and quality of the library was confirmed, then the Illumina sequencer was used for sequencing.

\section{Identification of differentially expressed genes}

The raw reads were first filtered and low-quality sequences were removed by the Trimmomatic software (18). Differential expression was assessed using Cufflinks software with fragments/kb of transcript per million fragments a protein-coding gene (19). The count number of each sample gene was standardized by DESeq software (20), the difference multiple was calculated, and the difference significance test of read number was carried out by NB. Differentially expressed genes were identified according to the following criteria: fold-change $>2$ and adjusted $\mathrm{P}$ value $<0.05$. 

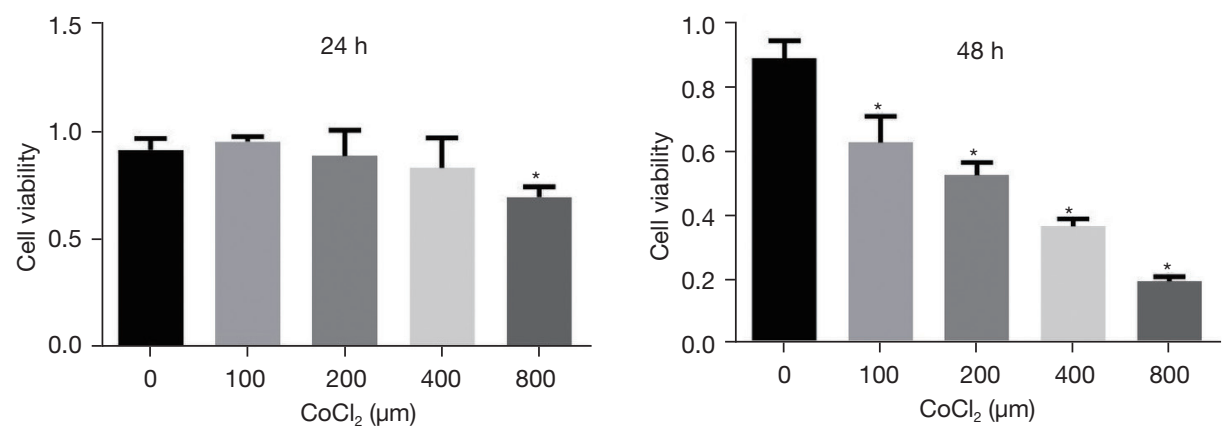

Figure 1 Effect of hypoxia on HSC-T6 cell activity. *, compared with the control group $(\mathrm{P}<0.05)$. CoCl 2 , cobalt chloride.

\section{GO and KEGG pathway analysis}

The differentially expressed mRNAs and miRNAs in HSC-T6 cells after hypoxia treatment were analyzed by GO analysis and KEGG pathway analysis. For GO analysis, the differentially expressed mRNAs and miRNAs were classified into 3 categories: biological process, cellular component, and molecular function. KEGG pathway analysis was performed to analyze the potential pathways enriched by the differentially expressed mRNAs and miRNAs.

\section{Gene co-expression network analysis}

According to the correlation between differentially expressed miRNAs and mRNAs, the regulatory relationship between miRNAs and mRNAs was determined by miRanda software, and the gene co-expression network was constructed.

\section{Statistical analysis}

All data were expressed as $\bar{x} \pm \mathrm{s}$, and at least 3 independent experiments were carried out. The experimental data were plotted by GraphPad Prism software and statistically analyzed by SPSS 24 . The two-sample $t$-test and analysis of variance were used for normally distributed data, while the rank sum test was used for non-normally distributed data. $\mathrm{P}<0.05$ was considered statistically significant, and transcriptomic sequencing analyses were completed by Shanghai Ouyi Company.

\section{Results}

\section{Effect of bypoxia on the activity of HSC-T6 cells}

After HSC-T6 cells were treated with different concentrations of $\mathrm{CoCl}_{2}$, the results of the CCK-8 assay showed that the activity of HSC-T6 cells gradually decreased with the increase of $\mathrm{CoCl}_{2}$ concentration, mainly after 48 hours of culture $(\mathrm{P}<0.0001)$. At the same time, the survival rate of HSC-T6 cells also gradually decreased with the extension of the culture time $(\mathrm{P}<0.0001)$ (Figure 1).

\section{Effect of hypoxia on the expression of HSC-related factors}

As a key transcription factor regulating hypoxia response, the level of HIF-1 $\alpha$ can be used to reflect the degree of hypoxia in cells to a certain extent. The expression of HIF- $1 \alpha$ in each group after $\mathrm{CoCl}_{2}$ treatment was detected by RT-qPCR. The results suggested that compared with the control group without $\mathrm{CoCl}_{2}$ treatment, the mRNA expression of HIF- $1 \alpha$ in $\mathrm{CoCl}_{2}$ treated HSC-T6 cells gradually increased with the increase of $\mathrm{CoCl}_{2}$ concentration ( $\mathrm{P}=0.0008,0.0308$, and 0.0064 , respectively), which was also accompanied by an increase in collagen I mRNA expression $(\mathrm{P}=0.0161,0.0024,0.038$, and 0.0164 , respectively) (Figure 2).

\section{Hypoxia causes the activation of HSCs}

In order to further clarify the mechanism of HSCs activation induced by HIF- $1 \alpha$, we detected the expression of TGF- $\beta 1$ and its downstream factors in each group. The results showed that compared with the control group, the expression of TGF- $\beta 1$ and Smad7 gradually increased in $\mathrm{CoCl}_{2}$ treated HSC-T6 cells with the increase of $\mathrm{CoCl}_{2}$ concentration $(\mathrm{P}=0.004)$. In addition, the experiment also explored the role of apoptosis and anti-apoptotic factors in HSC activation. The results of western blot showed that the level of HIF- $1 \alpha$ protein increased with the increase of $\mathrm{CoCl}_{2}$ concentration $(\mathrm{P}<0.0001)$ (Figure 3), which was 

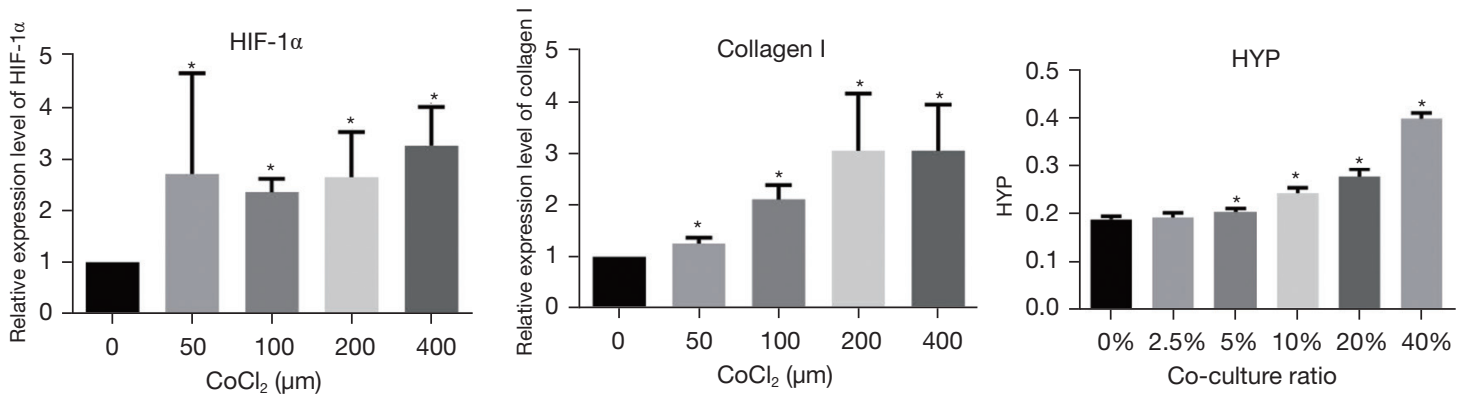

Figure 2 Effects of hypoxia on HIF-1 $\alpha$ and collagen I expression. * , compared with the control group $(\mathrm{P}<0.05)$. HIF-1 $\alpha$, hypoxia inducible factor-1 alpha, HYP, hydroxyproline.

consistent with the results of RT-qPCR. Furthermore, the expression of apoptosis factors Bax and caspase- 3 increased, while the level of the anti-apoptosis factor Bcl-2 decreased $(\mathrm{P}<0.0001)$ (Figure 3). We also found that the ratio of $\mathrm{Bcl}-$ 2/Bax increased with the increase of $\mathrm{CoCl}_{2}$ concentration $(\mathrm{P}<0.0001)$ (Figure 3).

\section{RNA quality analysis}

The purity of each group of RNA detected by the NanoDrop 2000 spectrophotometer indicated that the ratio of OD 260/280 of all RNA samples was between 1.8-2.2 (Table 3). Two clear, complete, and bright electrophoretic bands could be seen in agarose gel electrophoresis, with 28s ribosome above and $18 \mathrm{~s}$ ribosome below. The width ratio of the 2 electrophoretic bands was about 2:1 (Figure S1, Figure S2). The Agilent 2100 results indicated that each group had RNA integrity (RIN) $=10$ (Figure S1, Figure S2), which met the condition of RIN $\geq 7$ and the requirements for sequencing. Therefore, follow-up experiments could be carried out.

\section{Differentially expressed miRNAs and mRNAs}

MiRNA and mRNA expression levels between the hypoxia treatment groups and control groups was analyzed by the DESeq algorithm, and differentially expressed miRNAs (DEmiRNAs) and mRNAs (DEmRNAs) were identified. A total of 54 miRNAs and 1,423 mRNAs were identified as differentially expressed between the 2 groups through gene sequencing analysis. Among the 54 miRNAs, 20 were upregulated and 34 were downregulated. Of the 1,423 mRNAs, 685 were upregulated and 738 were downregulated (Figure 4). The top 20 differentially expressed genes are presented in Table 4. A volcano plot was used to identify DEmiRNAs and DEmRNAs between the 2 groups, where red represents upregulation of significantly different miRNAs and green represents downregulation of significantly different miRNAs.

\section{GO analysis}

GO analysis indicated that the differentially expressed miRNAs were associated with numerous important biological processes, cellular components, and molecular functions. The present study indicated that the biological functions of differentially expressed miRNAs mainly included processes such as signal transduction, biological function, and protein phosphorylation. In terms of cellular components, they mainly included cell matrix and cellular components. The molecular functions mainly included protein binding and protein dimerization (Figure 5).

\section{KEGG analysis}

KEGG analysis was used to investigate the pathways associated with important differentially expressed genes. There were 132 signaling pathways for the hypoxia treatment groups. The signal transduction pathways enriched by differentially expressed miRNA target genes included the mitogen-activated protein kinase (MAPK) signaling pathway, the extracellular matrix (ECM) receptor interaction pathway, and the focal adhesion pathway (Figure 6).

\section{MiRNA-mRNA co-expression network}

The miRNA-mRNA co-expression network was constructed based on the differentially expressed genes detected between the hypoxia treatment groups and control groups. The study found that a total of 244 mRNAs were 

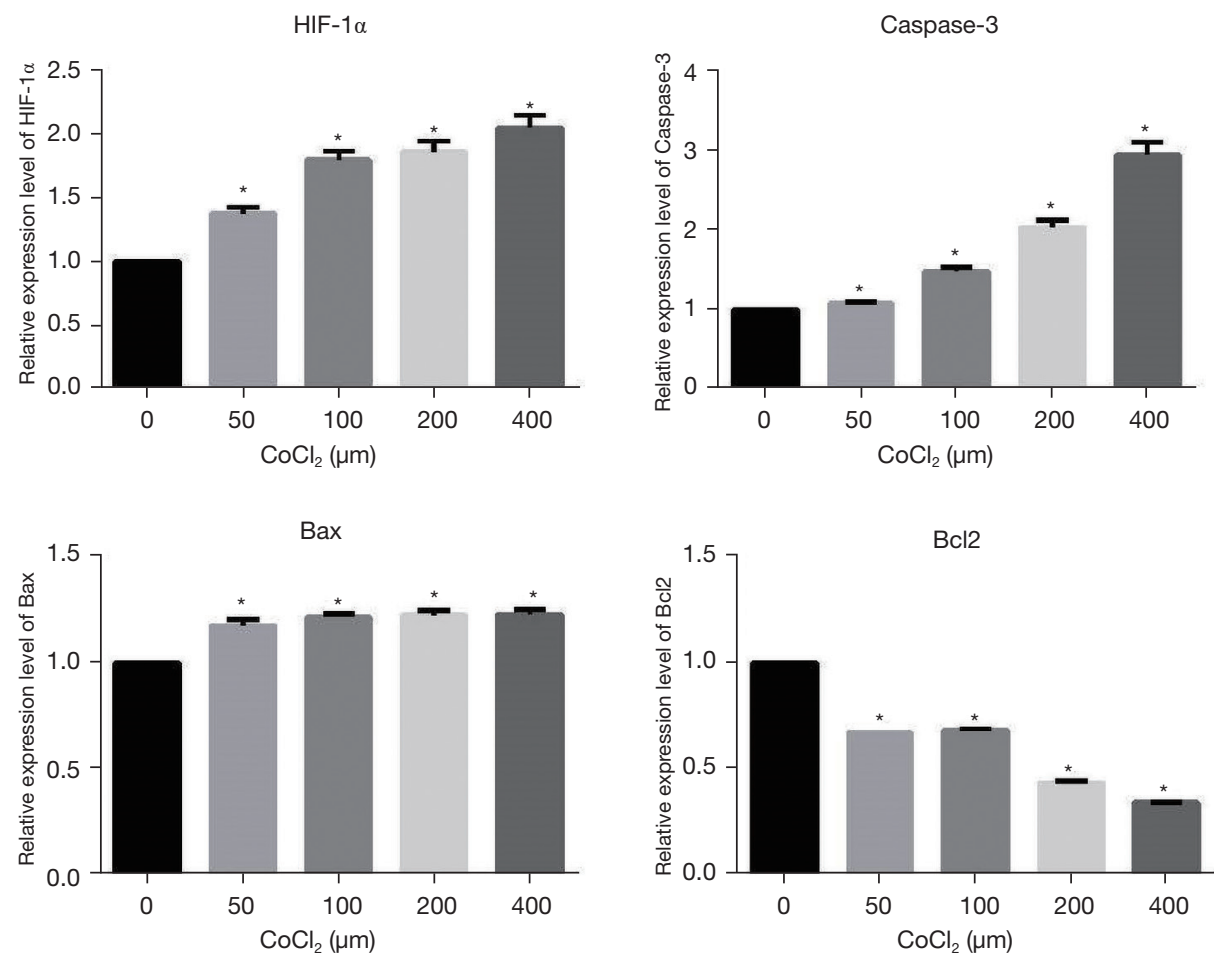

$\mathrm{Bcl} 2 / \mathrm{bax}$

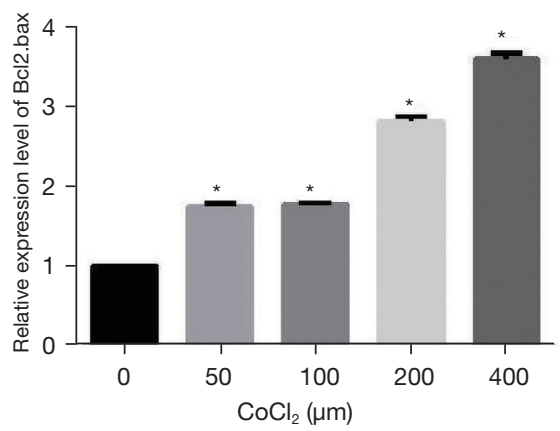

Figure 3 Effects of hypoxia on HIF-1 $\alpha$, caspase-3, Bax, and Bcl-2 expression. *, compared with the control group $(\mathrm{P}<0.05)$. HIF-1 $\alpha$, hypoxia inducible factor-1 alpha.

Table 3 RNA concentration in each group

\begin{tabular}{lccc}
\hline Groups & Concentration $(\mu \mathrm{g} / \mu \mathrm{L})$ & $\mathrm{A} 260 / 280$ & $\mathrm{~A} 260 / 230$ \\
\hline con-1 & 0.6858 & 2.13 & 1.96 \\
con-2 & 0.7850 & 2.15 & 1.97 \\
con-3 & 0.8977 & 2.13 & 2.18 \\
tre-1 & 0.7276 & 2.11 & 1.85 \\
tre-2 & 0.4563 & 2.15 & 2.10 \\
tre-3 & 0.8151 & 2.16 & 2.19 \\
\hline
\end{tabular}

combined with the significantly differentially expressed miRNAs in the sample. As shown in Figure 6, we found that a complex regulatory network is formed between miRNAs and mRNAs. It can be seen that one miRNA can be attached to multiple mRNAs. Similarly, one mRNA can also regulate the expression of multiple miRNAs. For example, rno-miR-351-5p can be regulated by many mRNAs, such as Cspg4, Col4a6, Cdh3, Chrd, E2f2, and Usp2, while Cspg4 not only regulates rno-miR-351-5p, but also regulates miRNAs such as rno-miR-702-3p, novel112_mature, and 

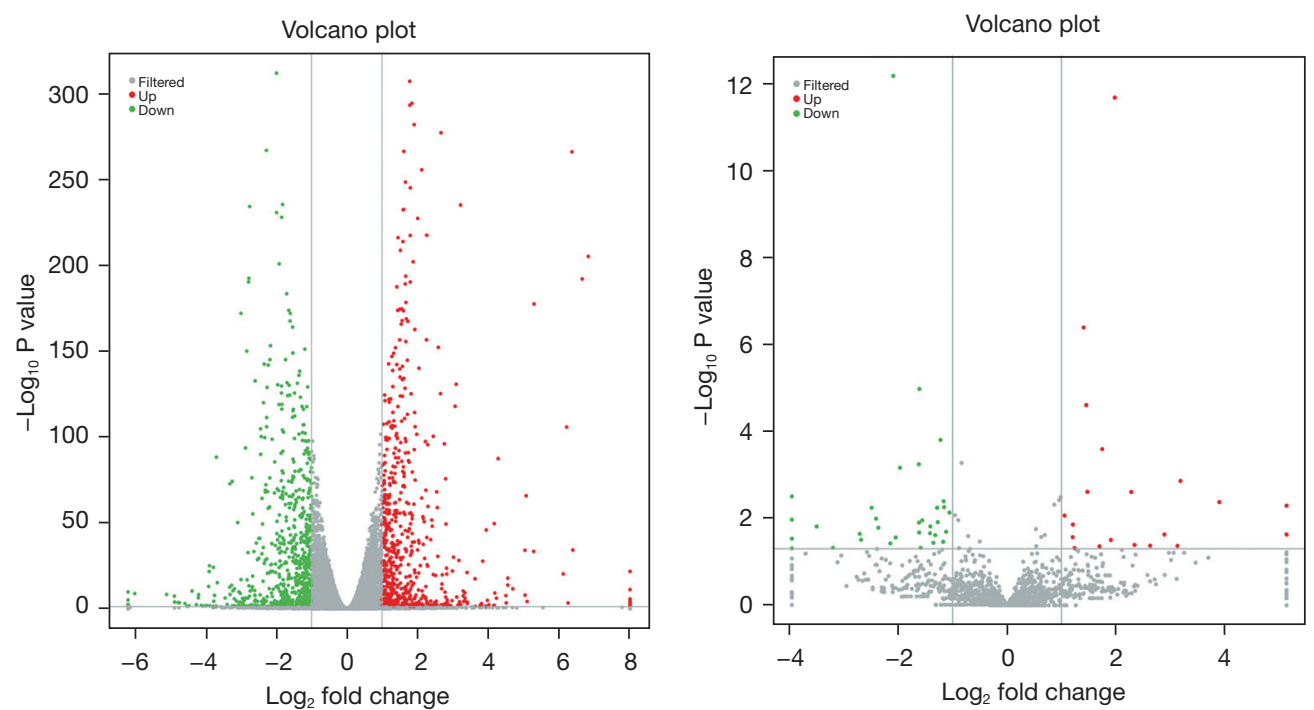

Figure 4 DEmRNAs and DEmiRNAs between the hypoxia treatment groups and control groups. The volcano plot includes all of the DEmRNAs and DEmiRNAs in the 2 groups. Red represents upregulation of DEmRNAs and DEmiRNAs, while green represents downregulation of DEmRNAs and DEmiRNAs. Gray represents non-differential mRNAs and miRNAs. DE, differentially expressed.

Table 4 Top 20 differentially expressed (DE) miRNAs between the hypoxia treatment groups and control groups

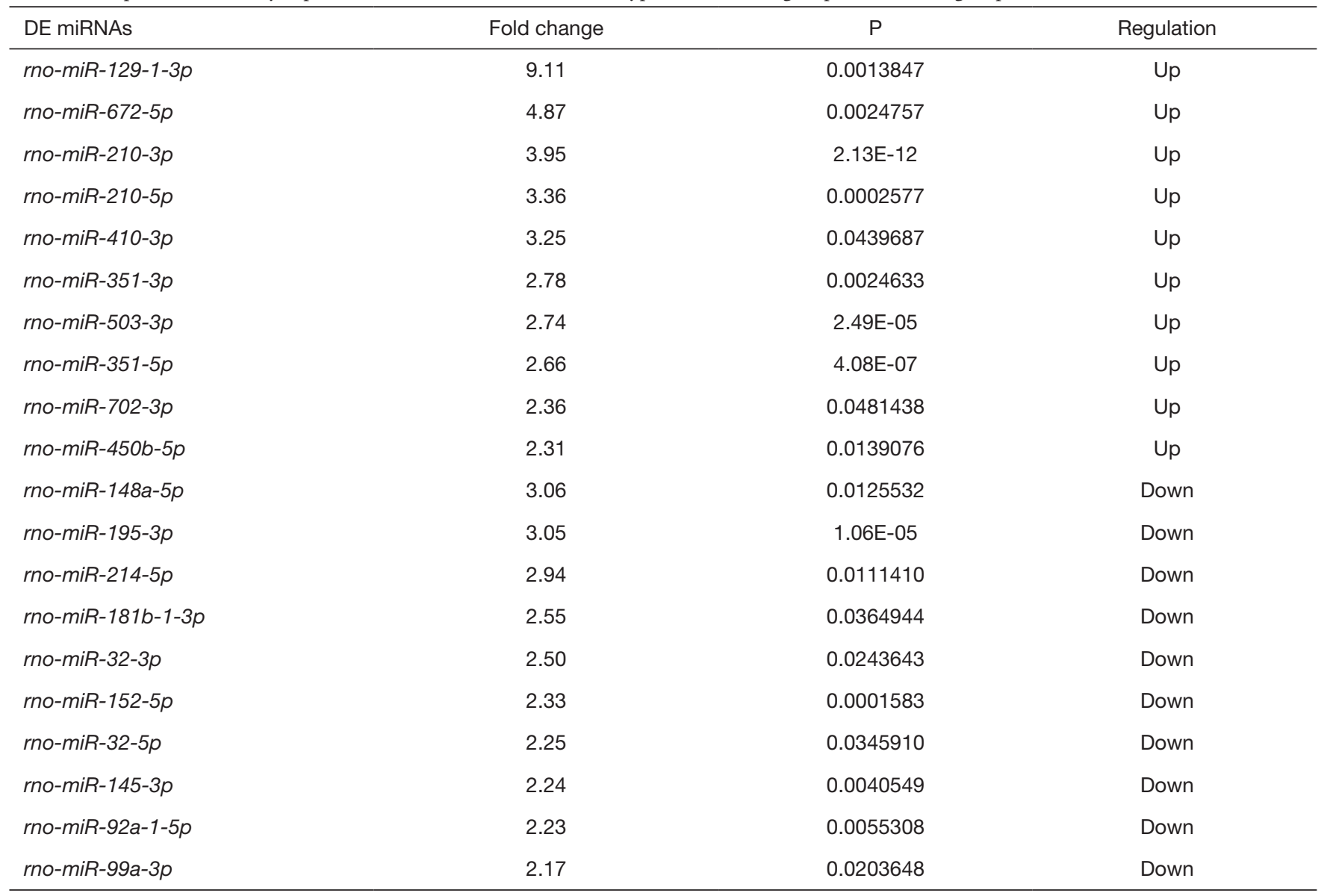




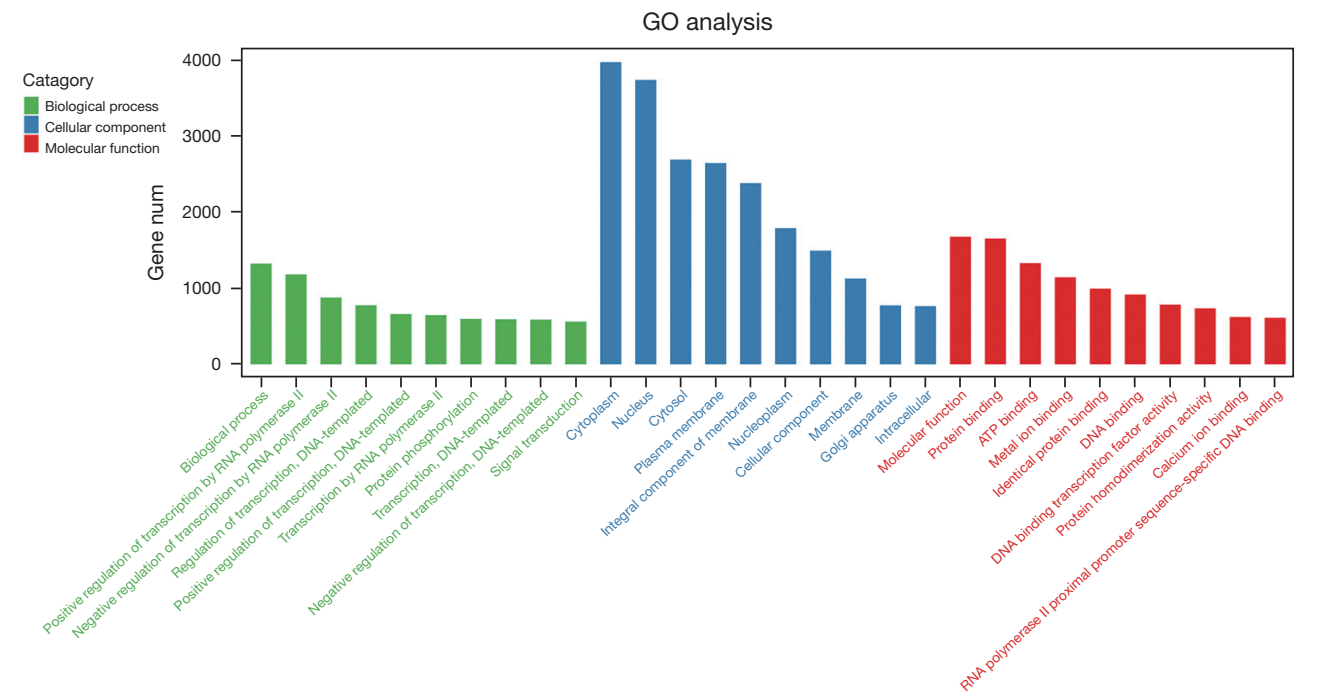

Figure 5 GO analysis of the differentially expressed miRNA. The horizontal axis is the name of the GO item, and the vertical axis is the number of genes enriched by the GO item. GO, Gene Ontology.

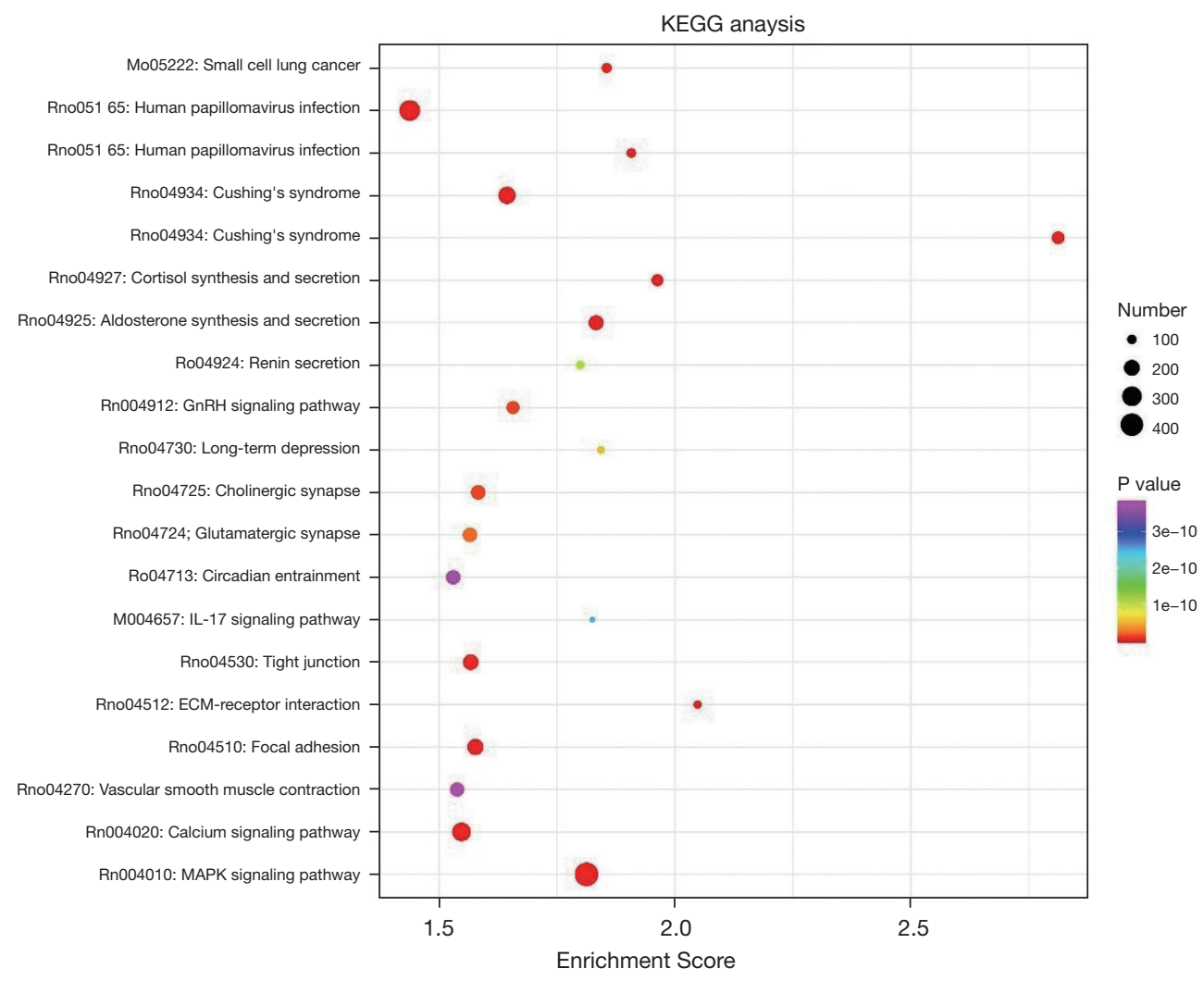

Figure 6 KEGG analysis of the differentially expressed miRNA. Each dot in the figure corresponds to a pathway, and the colors are sorted by red, orange, yellow, green, blue, indigo, and purple corresponding to the $\mathrm{P}$ value from small to large. The smaller the $\mathrm{P}$ value, the more the color tends to red. The larger the dot, the more the number of genes in the pathway. KEGG, Kyoto Encyclopedia of Genes and Genomes. 


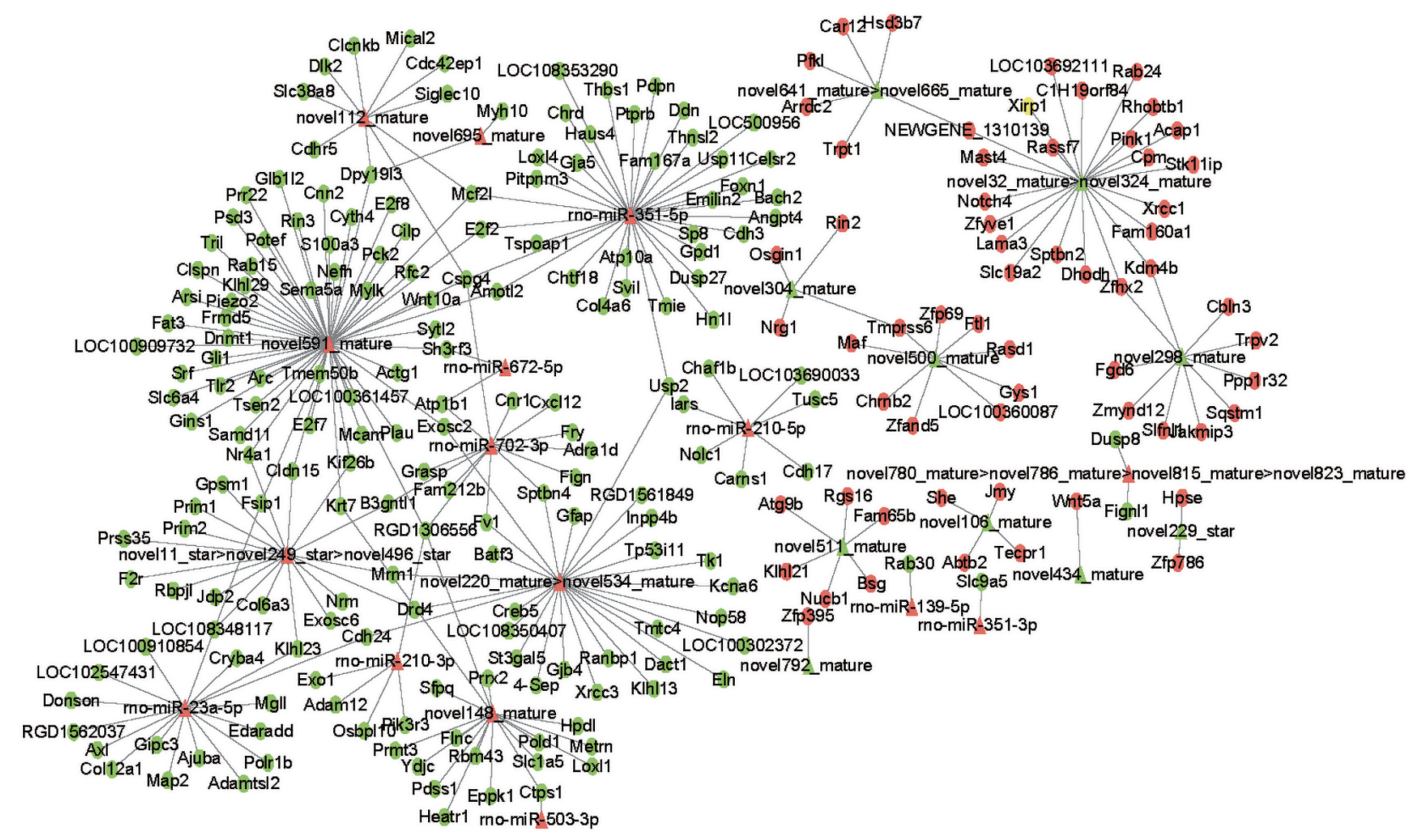

Figure 7 MiRNA-mRNA co-expression network. In the figure, miRNAs are triangles, and mRNAs are circles. Red represents upregulation and green represents downregulation. The larger the graph, the more nodes connected to it.

novel591_mature (Figure 7).

\section{RT-PCR verification results}

The results of RT-PCR showed that compared with the control group, the expression levels of miR-23a-5p, miR$145-3 p$, and miR-702-3p in HSC-T6 cells after hypoxia treatment were significantly downregulated $(\mathrm{P}<0.001)$, while the expression of miR-351-5p was significantly upregulated $(\mathrm{P}<0.001)$. This conclusion is similar to the results of gene sequencing, which verifies the experimental results (Figure 8).

\section{Discussion}

Here, we used $\mathrm{CoCl}_{2}$ to clarify the relationship between hypoxia and HSC activation and the related mechanisms, as well as the changes of miRNAs and mRNAs in HSC-T6 cells under hypoxia regulation. It was found that hypoxia can activate HSC-T6 cells, accompanied by an upregulation of the expression of matrix-related factors. Furthermore, hypoxia activated HSCs mainly through HIF- $1 \alpha$-mediated TGF- $\beta$ signal transduction. RNA-sequencing analysis showed that compared with the control group, a total of 54 miRNAs and 1,423 mRNAs were identified in HSC-T6 cells after hypoxia treatment. Further bioinformatics analysis showed that the differentially expressed miRNAs were related to matrix synthesis and signal transduction, and the results of gene sequencing were verified by RTPCR. To the best of our knowledge, the present study is the first to use RNA-sequencing and bioinformatics analysis to clarify then verify the expression of miRNAs in HSC-T6 cells after hypoxia.

Hypoxia is an important factor that causes cell damage and liver damage (21). Our previous studies have shown that hypoxia exists in mouse models of cirrhosis (22), and other studies presented that hypoxia can activate HSCs $(23,24)$. The study reported that hypoxia could induce the activation of HSCs through autophagy, while autophagy could control intracellular homeostasis through lysosomal enzyme self-digestion (5). Thus, the studies presented that 

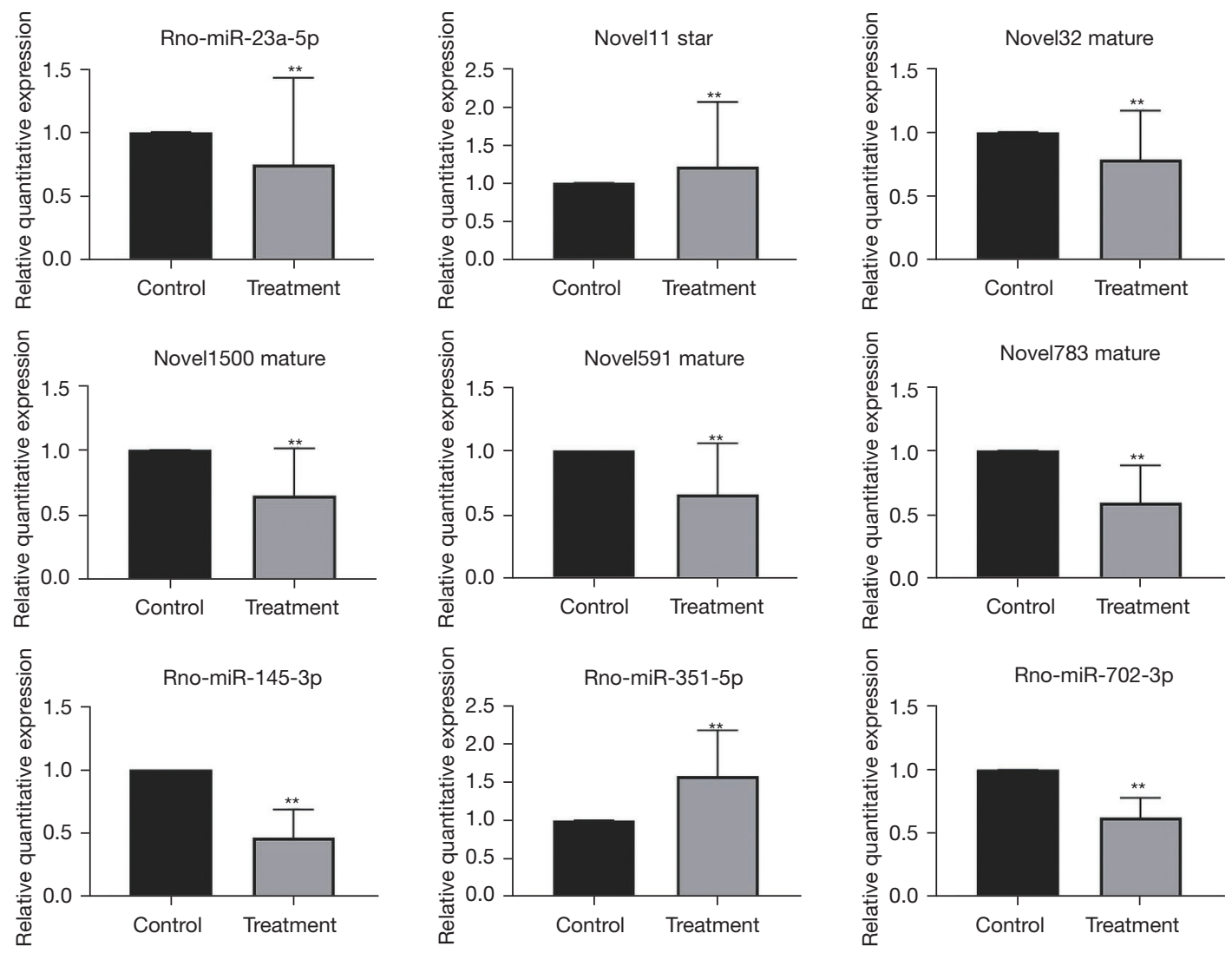

Figure 8 The mRNA expression levels determined by RT-qPCR. **, compared with the control group $(\mathrm{P}<0.01)$. RT-qPCR, reverse transcription quantitative polymerase chain reaction.

several autophagy related pathways were contributed to activation of HSCs under hypoxia condition, including $\mathrm{Ca}^{2+}-5$ '-adenosine monophosphate-activated protein kinase (AMPK)-mammalian target of rapamycin (mTOR), protein kinase $\mathrm{C}$-theta (PKC $\theta$ ) activation (5), and the plasmacytoma variant translocation 1 (PVT1)-miR-152-autophagy-related gene 14 signaling pathway (25). Additionally, other studies found hypoxia directly or indirectly inhibits the expression of peroxisome proliferator-activated receptors (PPAR) by inducing Phosphatidylinositol-4,5-bisphosphate 3-kinase $(\mathrm{PI} 3 \mathrm{~K}) /$ protein kinase B (Akt) signal transduction, which may be play a role in the activation of HSCs induced by hypoxia (4). Liu et al. pointed out BCL2/adenovirus E1B $19 \mathrm{kDa}$ interacting protein 3 (Bnip3) interacts with vimentin could regulated autophagy of hepatic stellate cells (26). HIF$1 \alpha$ may make the body adapt to the hypoxia environment, since it could maintain the survival and function of cells by regulating the expression of genes related to cell proliferation, energy metabolism, cell migration, and angiogenesis $(27,28)$. Hong et al. (29) found that nuclear transport of HIF-1 molecule, and autophagy and activation of HSC were apparently inhibited in hypoxia-induced HSC, as trimethylation of $\mathrm{H} 3$ histone on lysine 4 ( $\mathrm{H} 3 \mathrm{~K} 4 \mathrm{me} 3)$ histone methylation was inhibited by methylthioadenosine (MTA), suggesting that histone methylation modification plays an important role in HIF-1 signaling cascade to regulate cell activities. The interplay between HIF1- $\alpha$ and Rho-associated coiled-coil-forming kinase 1 (ROCK1) was reported as a critical factor that regulates cell proliferation and collagen synthesis in rat HSCs under hypoxia (3). Copple $e t$ al. demonstrated that hypoxia, through activation of HIF-1 $\alpha$, regulates the expression of genes that may alter the sensitivity of HSCs, that important for collagen deposition and angiogenesis (21). In addition to exosomes derived from HSCs contained glycolysis-related proteins and were regulated by HIF- $1 \alpha$, while the mechanism was also involved in the activation and metabolic switch of HSCs and other liver nonparenchymal cells (30). In this study, we found that the expression of HIF-1 $\alpha$ increased with the increase of $\mathrm{CoCl}_{2}$ concentration, and the increase of HIF- 
$1 \alpha$ was accompanied by the increase of collagen I level, which might be related to hypoxia regulating the expression of extracellular matrix protein genes such as fibronectin and collagen I through HIF-1 $\alpha$ (21). The results showed that the expression of TGF- $\beta 1$ and Smad7 mRNA gradually increased with the increase of $\mathrm{CoCl}_{2}$ concentration after hypoxia treatment. The balance between cell activation and apoptosis plays an important role in liver fibrosis, whist the inactivation of HSCs is related to the upregulation of antiapoptosis genes $(31,32)$. In addition, the downregulation of Bcl-2 expression also reflected the HSC inactivation to a certain extent. Further calculation of the Bcl-2/Bax ratio showed that the anti-apoptotic factor Bcl-2 was dominant after hypoxia treatment, which may also be the reason for the upregulation of TGF- $\beta 1$ expression.

Increasing studies have shown that miRNAs play an important role in HSCs activation and liver fibrosis (33-35), but limited studies focused on the under hypoxic conditions. The previous study clarified that the miRNA-21was involved in arsenite-induced hepatic fibrosis through aberrant cross-talk of hepatocytes and HSCs, through the HIF$1 \alpha$ /vascular endothelial growth factor (VEGF) signaling pathway (36). In our study, we screened the differential expression profiles of miRNAs and mRNAs in the control and hypoxia treatment groups based on RNA-sequencing. In a carbon tetrachloride-induced liver fibrosis model, a total of 71 DEmiRNAs were detected by high-throughput sequencing, and these DEmiRNAs were involved in matrix synthesis and signal pathway conduction (37). The functional analyses presented DEmiRNAs were closely related to matrix synthesis, signal transduction, and protein binding. A total of 132 signaling pathways might be essential for the hypoxia treatment groups. Several of these pathways were already known to be involved in the progression of liver fibrosis, such as the MAPK, focal adhesion, Wnt, p53, mTOR, and PI3K-Akt signaling pathways $(38,39)$. The KEGG analyses showed that the pathways included the MAPK signaling pathway, the ECM receptor interaction pathway, and the focal adhesion pathway. Therefore, the imbalance of miRNA regulation in MAPK signal transduction may be related to the hypoxia regulation of HSCs. Further, miR-351-5p was significantly increased in HSC-T6 cells treated with hypoxia compared to the control group through RT-PCR to validation. Finally, the miRNA-mRNA network presented the complex interconnections and effects between these two and further shown the biological functions of miRNAs.

There are some limitations in the present study. Firstly, further experiments are required to study the detailed functions and mechanisms of these miRNAs. Secondly, no in vivo research was involved in this study, and HSC-6 cells were from donation, thus, further investigations of the experiment and cells are needed. Thirdly, next-generation sequencing technology itself has certain limitations, which may be improved with the further development of the technology.

\section{Conclusions}

In summary, our results indicated that a hypoxic microenvironment can activate HSCs, which may be related to the promotion of collagen fiber and hydroxyproline production mediated by HIF-1 $\alpha$. The study provided the information on related miRNAs, signaling pathways, and co-expression networks in HSCs after hypoxia treatment, suggesting novel insights and potential biomarkers for the early diagnosis and treatment of HSC activation and liver fibrosis.

\section{Acknowledgments}

Funding: The present study was financially supported by the National Natural Science Foundation of China (31570509), the National Natural Science Foundation of China (81800528), the Major Science and Technology Projects in Gansu Province (1602FKDA001), the Hospital Fund of The First Hospital of Lanzhou University (ldyyyn2018-41), and the Natural Science Foundation of Gansu Province (20JR10RA683).

\section{Footnote}

Reporting Checklist: The authors have completed the MDAR reporting checklist. Available at https://dx.doi. org/10.21037/atm-21-4215

Data Sharing Statement: Available at https://dx.doi. org/10.21037/atm-21-4215

Conflicts of Interest: All authors have completed the ICMJE uniform disclosure form (available at https://dx.doi. org/10.21037/atm-21-4215). The authors have no conflicts of interest to declare.

Etbical Statement: The authors are accountable for all aspects of the work in ensuring that questions related 
to the accuracy or integrity of any part of the work are appropriately investigated and resolved.

Open Access Statement: This is an Open Access article distributed in accordance with the Creative Commons Attribution-NonCommercial-NoDerivs 4.0 International License (CC BY-NC-ND 4.0), which permits the noncommercial replication and distribution of the article with the strict proviso that no changes or edits are made and the original work is properly cited (including links to both the formal publication through the relevant DOI and the license). See: https://creativecommons.org/licenses/by-nc-nd/4.0/.

\section{References}

1. Lai M, Afdhal NH. Liver Fibrosis Determination. Gastroenterol Clin North Am 2019;48:281-9.

2. Shang L, Hosseini M, Liu X, et al. Human hepatic stellate cell isolation and characterization. J Gastroenterol 2018;53:6-17.

3. $\mathrm{Hu} \mathrm{Y}, \mathrm{Hu} \mathrm{D}, \mathrm{Yu} \mathrm{H}$, et al. Hypoxia-inducible factor $1 \alpha$ and ROCK1 regulate proliferation and collagen synthesis in hepatic stellate cells under hypoxia. Mol Med Rep 2018;18:3997-4003.

4. Zhang Q, Xiang S, Liu Q, et al. PPAR $\gamma$ Antagonizes Hypoxia-Induced Activation of Hepatic Stellate Cell through Cross Mediating PI3K/AKT and cGMP/PKG Signaling. PPAR Res 2018;2018:6970407.

5. Jin $\mathrm{Y}, \mathrm{Bai} \mathrm{Y}, \mathrm{Ni} \mathrm{H}$, et al. Activation of autophagy through calcium-dependent AMPK/mTOR and PKC $\theta$ pathway causes activation of rat hepatic stellate cells under hypoxic stress. FEBS Lett 2016;590:672-82.

6. Hernández A, Reyes D, Geng Y, et al. Extracellular vesicles derived from fat-laden hepatocytes undergoing chemical hypoxia promote a pro-fibrotic phenotype in hepatic stellate cells. Biochim Biophys Acta Mol Basis Dis 2020;1866:165857.

7. Szabo G, Bala S. MicroRNAs in liver disease. Nat Rev Gastroenterol Hepatol 2013;10:542-52.

8. Bandiera S, Pfeffer S, Baumert TF, et al. miR-122--a key factor and therapeutic target in liver disease. J Hepatol 2015;62:448-57.

9. Dewidar B, Meyer C, Dooley S, et al. TGF- $\beta$ in Hepatic Stellate Cell Activation and Liver Fibrogenesis-Updated 2019. Cells 2019;8:1419.

10. Zhang T, Yang Z, Kusumanchi P, et al. Critical Role of microRNA-21 in the Pathogenesis of Liver Diseases. Front Med (Lausanne) 2020;7:7.
11. Men R, Wen M, Zhao M, et al. MircoRNA-145 promotes activation of hepatic stellate cells via targeting krüppel-like factor 4. Sci Rep 2017;7:40468.

12. Ge S, Zhang L, Xie J, et al. MicroRNA-146b regulates hepatic stellate cell activation via targeting of KLF4. Ann Hepatol 2016;15:918-28.

13. Ma L, Yang X, Wei R, et al. MicroRNA-214 promotes hepatic stellate cell activation and liver fibrosis by suppressing Sufu expression. Cell Death Dis 2018;9:718.

14. Tao L, Xue D, Shen D, et al. MicroRNA-942 mediates hepatic stellate cell activation by regulating BAMBI expression in human liver fibrosis. Arch Toxicol 2018;92:2935-46.

15. Li J, Ghazwani M, Zhang Y, et al. miR-122 regulates collagen production via targeting hepatic stellate cells and suppressing P4HA1 expression. J Hepatol 2013;58:522-8.

16. Ezhilarasan D. MicroRNA interplay between hepatic stellate cell quiescence and activation. Eur J Pharmacol 2020;885:173507.

17. Kong $X$, Zhou W, Wan JB, et al. An Integrative Thrombosis Network: Visualization and Topological Analysis. Evid Based Complement Alternat Med 2015;2015:265303.

18. Bolger AM, Lohse M, Usadel B. Trimmomatic: a flexible trimmer for Illumina sequence data. Bioinformatics 2014;30:2114-20.

19. Roberts A, Pimentel H, Trapnell C, et al. Identification of novel transcripts in annotated genomes using RNA-Seq. Bioinformatics 2011;27:2325-9.

20. Anders S, McCarthy DJ, Chen Y, et al. Count-based differential expression analysis of RNA sequencing data using R and Bioconductor. Nat Protoc 2013;8:1765-86.

21. Copple BL, Bai S, Burgoon LD, et al. Hypoxia-inducible factor- $1 \alpha$ regulates the expression of genes in hypoxic hepatic stellate cells important for collagen deposition and angiogenesis. Liver Int 2011;31:230-44.

22. Zhang L, Zhou D, Li J, et al. Effects of Bone MarrowDerived Mesenchymal Stem Cells on Hypoxia and the Transforming Growth Factor beta 1 (TGF $\beta-1$ ) and SMADs Pathway in a Mouse Model of Cirrhosis. Med Sci Monit 2019;25:7182-90.

23. Wang Y, Huang Y, Guan F, et al. Hypoxia-inducible factor1alpha and MAPK co-regulate activation of hepatic stellate cells upon hypoxia stimulation. PLoS One 2013;8:e74051.

24. Nath B, Szabo G. Hypoxia and hypoxia inducible factors: diverse roles in liver diseases. Hepatology 2012;55:622-33.

25. Yu F, Dong B, Dong P, et al. Hypoxia induces the activation of hepatic stellate cells through the PVT1- 
miR-152-ATG14 signaling pathway. Mol Cell Biochem 2020;465:115-23.

26. Liu J, Xie Y, Cui Z, et al. Bnip3 interacts with vimentin, an intermediate filament protein, and regulates autophagy of hepatic stellate cells. Aging (Albany NY) 2020;13:957-72.

27. Koh MY, Gagea M, Sargis T, et al. A new HIF-1 $\alpha$ / RANTES-driven pathway to hepatocellular carcinoma mediated by germline haploinsufficiency of SART1/HAF in mice. Hepatology 2016;63:1576-91.

28. Ju C, Colgan SP, Eltzschig HK. Hypoxia-inducible factors as molecular targets for liver diseases. J Mol Med (Berl) 2016;94:613-27.

29. Hong F, Wan L, Liu J, et al. Histone methylation regulates Hif-1 signaling cascade in activation of hepatic stellate cells. FEBS Open Bio 2018;8:406-15.

30. Wan L, Xia T, Du Y, et al. Exosomes from activated hepatic stellate cells contain GLUT1 and PKM2: a role for exosomes in metabolic switch of liver nonparenchymal cells. FASEB J 2019;33:8530-42.

31. Tsuchida T, Friedman SL. Mechanisms of hepatic stellate cell activation. Nat Rev Gastroenterol Hepatol 2017;14:397-411.

32. Kisseleva T, Cong M, Paik Y, et al. Myofibroblasts revert to an inactive phenotype during regression of liver fibrosis. Proc Natl Acad Sci U S A 2012;109:9448-53.

Cite this article as: Zhang L, Gao J, Zhou D, Wang X, Li J, Wang J, Chen H, Xie X, Chen T. Profiles of messenger RNAs and MicroRNAs in hypoxia-induced hepatic stellate cells. Ann Transl Med 2021;9(18):1451. doi: 10.21037/atm-21-4215
33. Ezhilarasan D, Sokal E, Najimi M. Hepatic fibrosis: It is time to go with hepatic stellate cell-specific therapeutic targets. Hepatobiliary Pancreat Dis Int 2018;17:192-7.

34. Hua S, Quan Y, Zhan M, et al. miR-125b-5p inhibits cell proliferation, migration, and invasion in hepatocellular carcinoma via targeting TXNRD1. Cancer Cell Int 2019;19:203.

35. Chen X, Zhang D, Wang Y, et al. Synergistic antifibrotic effects of miR-451 with miR-185 partly by co-targeting EphB2 on hepatic stellate cells. Cell Death Dis 2020;11:402.

36. Sun J, Shi L, Xiao T, et al. microRNA-21, via the HIF-1 $\alpha$ / VEGF signaling pathway, is involved in arsenite-induced hepatic fibrosis through aberrant cross-talk of hepatocytes and hepatic stellate cells. Chemosphere 2021;266:129177.

37. Zhang Y, Liu J, Ma Y, et al. Integration of high-throughput data of microRNA and mRNA expression profiles reveals novel insights into the mechanism of liver fibrosis. Mol Med Rep 2019;19:115-24.

38. Zhao XK, Yu L, Cheng ML, et al. Focal Adhesion Kinase Regulates Hepatic Stellate Cell Activation and Liver Fibrosis. Sci Rep 2017;7:4032.

39. Wang Y, Ma J, Chen L, et al. Inhibition of Focal Adhesion Kinase on Hepatic Stellate-cell Adhesion and Migration. Am J Med Sci 2017;353:41-8. 


\section{Supplementary}
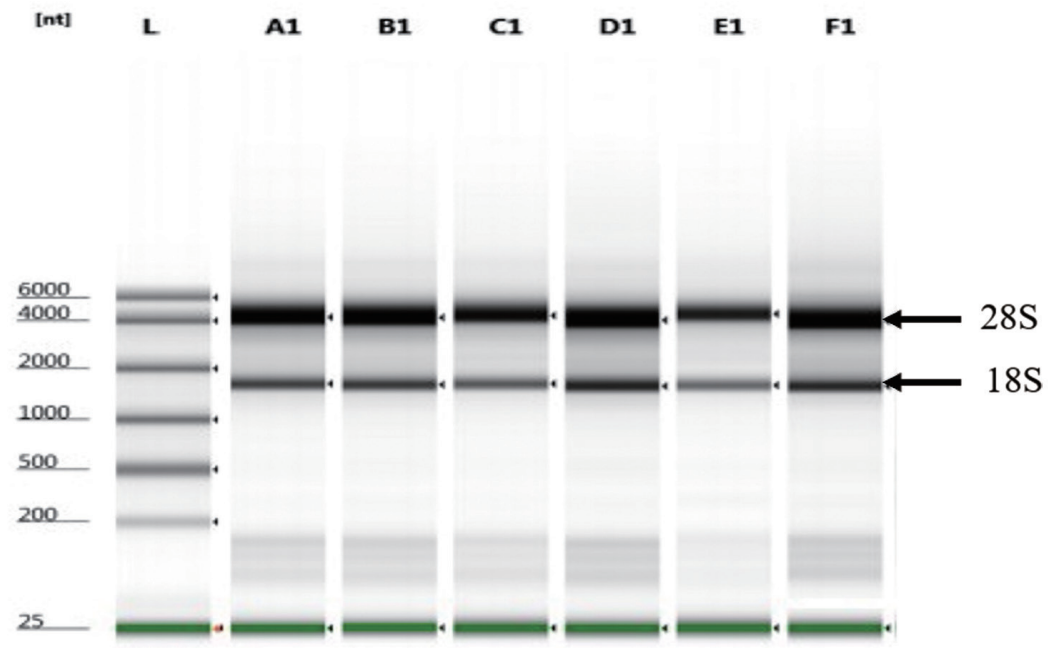

Figure S1 RNA gel electrophoresis diagram.

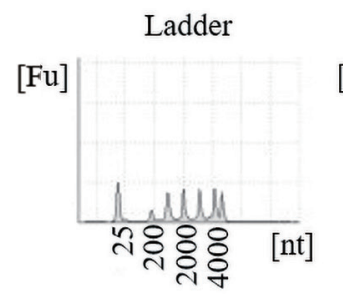

D1

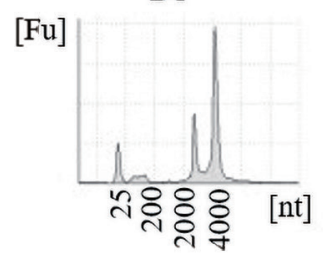

A1

$[\mathrm{Fu}]$

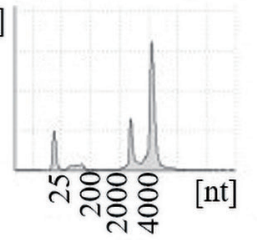

E1

$[\mathrm{Fu}]$

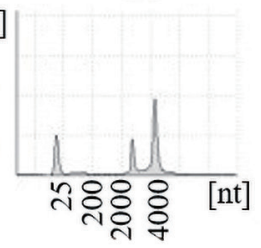

B1

$[\mathrm{Fu}]$

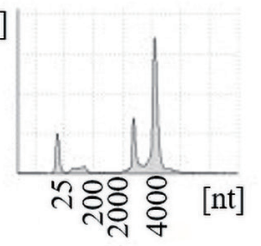

F1

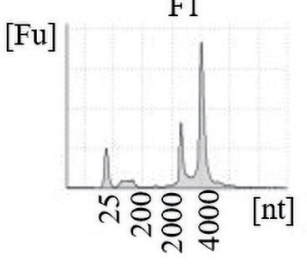

Figure S2 Agilent test results. 